\title{
Jorge Cuesta el ensayista
}

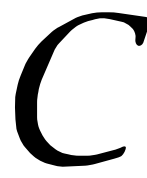

on una obra trunca y escasamente difundida, Jorge Cuesta ha sido una presencia constante en la literatura y, en general, en la cultura mexicana. La figura de Cuesta puede ser asimilada de distintas maneras: ya sea como el héroe romántico dueño de una envidiable leyenda negra, ya sea como el paradigma de independencia e integridad intelectual. La época en que Cuesta despliega su actividad intelectual es una etapa de auténtica refundación, en que la clase política heredera de la Revolución Mexicana busca hacer de la cultura un vínculo ideológico que modifique y fortalezca la identidad colectiva y que propicie lealtades al nuevo Estado. En este sentido, los rasgos dominantes del proyecto cultural posrevolucionario son el discurso nacionalista, la figura del intelectual al servicio del pueblo y el usufructo de un arte pedagógico y urilitario que debe servir como instrumento para la transformación social. La perspectiva de Cuesta, que confluye con la de sus amigos del grupo "Contemporáneos", significa un contrapeso de cosmopolitismo, rigor y autonomía del arte frente al concepto de cultura endogámico, político y utilitario que se promueve desde el poder.

Si bien Cuesta comparte ideas, gustos y aspiraciones con los demás miembros de su generación, su actividad pública es la más frontal y combativa de todos, debido a su distancia con la esfera del poder y a su propio temperamento. Cuesta fue una presencia polémica, que publicó numerosos artículos y ensayos sobre temas tan disímiles como la literatura, la música, la pintura, el teatro, la fi- losofía, la política o la psicología. Con su vasta curiosidad Cuesta cubre, en general con lucidez y vigor, muy distintos campos del conocimiento. Con este trabajo de reflexión no sólo suple la alarmante falta de pensadores especializados, sino que cumple una función cívica de traslación de los grandes temas de su tiempo en los diversos ámbitos del conocimiento a los terrenos más amplios de la vida pública. Su labor como precursor de muchos de los debates actuales todavía está por reconocerse, en parte por la dispersión de su obra, en parte por su voluntad, como el célebre descubridor de Torri, más de revelar que de explotar una veta de conocimiento. La obra crítica de Cuesta es un largo ejercicio de corrección: Cuesta busca revelar las distorsiones del pensamiento, las faltas de rigor lógico, los abusos del lenguaje y las fallas en la expresión que afectan y deterioran la vida interior y la vida pública.

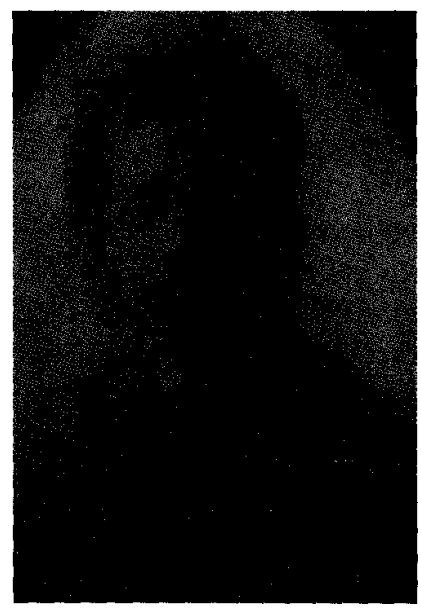

Jorge Cuesta en 1922 a su llegada a México 
Para Cuesta el arte, la crítica y la poesía son fuentes de sentido que ordenan lo caótico y que le otorgan una nueva significación, ajena a las leyes físicas y morales convencionales, pero no menos rigurosa y lógica. La función del pensamiento y el arte, por ende, no es la aceptación del mundo sino su interrogación. Esto implica cuestionar origen, costumbres, normas, ideas y valores e intentar un trabajo de reinvención, a partir de la razón y la conciencia de la libertad. Cuesta dignifica la crítica como una forma de conciencia y enriquecimiento de la actividad artística y de la vida, prácticamente como un ejercicio paralelo de creación. Para Cuesta, la crítica es acto de examen y ascesis interior, que se orienta, antes que nada, a esclarecer las propias pasiones.

Aunque los temas que trató Cuesta en sus ensayos son muy numerosos y en muchos de ellos es posible encontrar fructíferas ramificaciones $y$ premoniciones, existen, en mi opinión, tres temas fundamentales que definen el temperamento intelectual de Cuesta. Dichos temas son: uno, la defensa de la mezcla cultural como factor de evolución; dos, la reivindicación de la autonomía del arte y, tres, la reserva frente al potencial de barbarie y deshumanización de las ideologías en boga.

En primer lugar, como ensayista, Cuesta fue un pionero en la crítica de las barreras ideo- lógicas que lastraban el entendimiento de las obras y las culturas como productos universales. La inflexible "ley de Cuesta" que guió su actividad creativa y polémica podría formularse de la manera siguiente: las modernidades nacionales se nutren de lo universal y entre más fervientemente se intenta alimentar un nacionalismo mayor es su indigencia real y su cualidad gaseosa. Acorde con esta idea, la noción de culturas nacionales, a menudo concebida como metáfora unitiva por las élites, constituye un mecanismo compensatorio, una estilización de las culturas reales en donde "no se observa en lo nacional al hombre, sino a la excepción del hombre". Para Cuesta, empero, este bacilo nacionalista es contradictorio con la realidad genética de las civilizaciones y con la formación de naciones que, como México, devienen modernas a partir de un salto hacia fuera de sus condicionamientos y de una apuesta histórica por principios de valor universal. Esta reivindicación casi religiosa del carácter universal del pensamiento y el arte constituye la divisa central de su obra y marca tanto su íntima elección creativa, como su cruzada contra la intolerancia de las ideologías tribales y el contagio chauvinista.

En segundo lugar, Cuesta fue un tenaz defensor de la autonomía del arte, es decir de la independencia de una actividad que busca una forma peculiar de sentido y conocimien-

'Louis Paranabière Itineratio de una disidencia: Jorge Cuesta (1903-1942), México, Fondo de Cultura Económica, 1984. p. 210 
to y cuyas formas de operación y evaluación rebasan los criterios de la moral o la política. Por eso, el nacionalismo, el arte proletario y otras formas del arte dirigido son sus blancos preferidos. Con todo, como señala Paranabiere, "no se trata, como algunos han tenido la tentación de pensar, de una posición "política" de Cuesta sino de una posición "artística". Él no está en contra de la literatura proletaria porque sea proletaria, sino porque es otra cosa diferente a la literatura". Para Cuesta, la mentira, la invención, la fantasía del arte complementan y corrigen la realidad. Así, en su carácter contrafactual, en su despliegue de lucidez creadora, el arte y la literatura constituyen una crítica de la realidad y cumplen su auténtica función. Si la literatura es trascendencia y enriquecimiento de la realidad, no es extraño que esta estética disienta de arte dirigido. Con todo, no se trata únicamente de abogar por la fantasía o el delirio, la creación de un mundo artístico propio requiere de un dominio exhaustivo de la forma y de un rigor y cálculo muy próximos a los que requiere la ciencia.

Finalmente, Cuesta fue un lúcido observador de la vida política, que desconfía de la índole totalitaria de ideologías como el fascismo o el comunismo, que en ese entonces polarizaban la adhesión de los intelectuales. Su escepticismo hacia una resolución de la soledad del individuo en la comunidad política es espontáneo, para Cuesta, la comunidad sólo puede darse en la inteligencia y la sensibilidad. De ahí su tortuoso liberalismo, su anticomunismo y su desconfianza frente a la política de masas del cardenismo. Ante la edificación de leyes históricas infalibles; ante al surgimiento del hombre masa; ante los reflejos condicionados de la izquierda y ante la pretensión de hacer del arte un instrumento de la historia o de la ingeniería social, Cuesta expresa su controvertida preocupación y elige la marginali- dad y la disidencia como una oposición heroica de la razón y el albedrío personal.

Si bien, puede hablarse de grandes vertientes temáticas en la obra de Cuesta, en realidad su pensamiento es ambicioso y abarcador. Frente a la estrechez de las especialidades, Cuesta detenta una amplitud de perspectivas que rebasa el diletantismo y que remite a la idea alquímica de una correspondencia de las artes y las ciencias. Ciertamente, Cuesta no acepta que el conocimiento o, quizá habría que decir el sentido, se fragmente en campos incomunicados $y$, por eso, esgrime una curiosidad y una actividad intelectual proteicas que abarcan desde la escritura de poesía hasta la investigación de la química, pasando por el cultivo riguroso de la opinión en diversos campos de la vida social. Sus diversas actividades e intereses no son, pues, producto de un espíritu disperso sino, al contrario, aspectos de una vasta voluntad de conocimiento. La investigación en la materia, en el lenguaje y en la sociedad se complementan y contribuyen a dar sentido al mundo.

Los ensayos de Cuesta brindan la oportunidad de observar el proceso de razonamiento de un escritor centrífugo, atar cabos, imaginar correspondencias y disonancias y reconstruir con material más resistente su itinerario crítico y creativo. Con todo, la multiplicidad de sus intereses; la dificultad de un estilo incapaz de transigir con la simpleza; las claves secretas de un alma torturada son hechos que impiden la clasificación o la lectura lineal. A Cuesta no se acude para constatar el desarrollo gradual y reposado de una obra, sino para observar una inteligencia huraña y movediza cuyas únicas señas permanentes son la franqueza intelectual y una perspicacia punzante. Leer sus ensayos implica una feliz constatación del vigor de su rasero estético, de la animación de su hosco sentido común, 
de la final verticalidad de su controvertida visión política. Por ello, si los fragmentos que la historia literaria conserva han servido para una fácil mitificación, el peso del conjunto muestra la tarea de Cuesta no sólo como una recopilación de opiniones brillantes, sino como la manifestación de un temperamento intelectual auténticamente adelantado a su tiempo. Tal vez por ello, más allá de la oscuridad de su estilo o de la pátina que circunda algunos de sus debates, la obra de Cuesta aún no ha acusado recibo de caducidad y su abigarrada dialéctica y torturado liberalismo todavía guardan la virtud de irritar e instruir. Armando González Torres

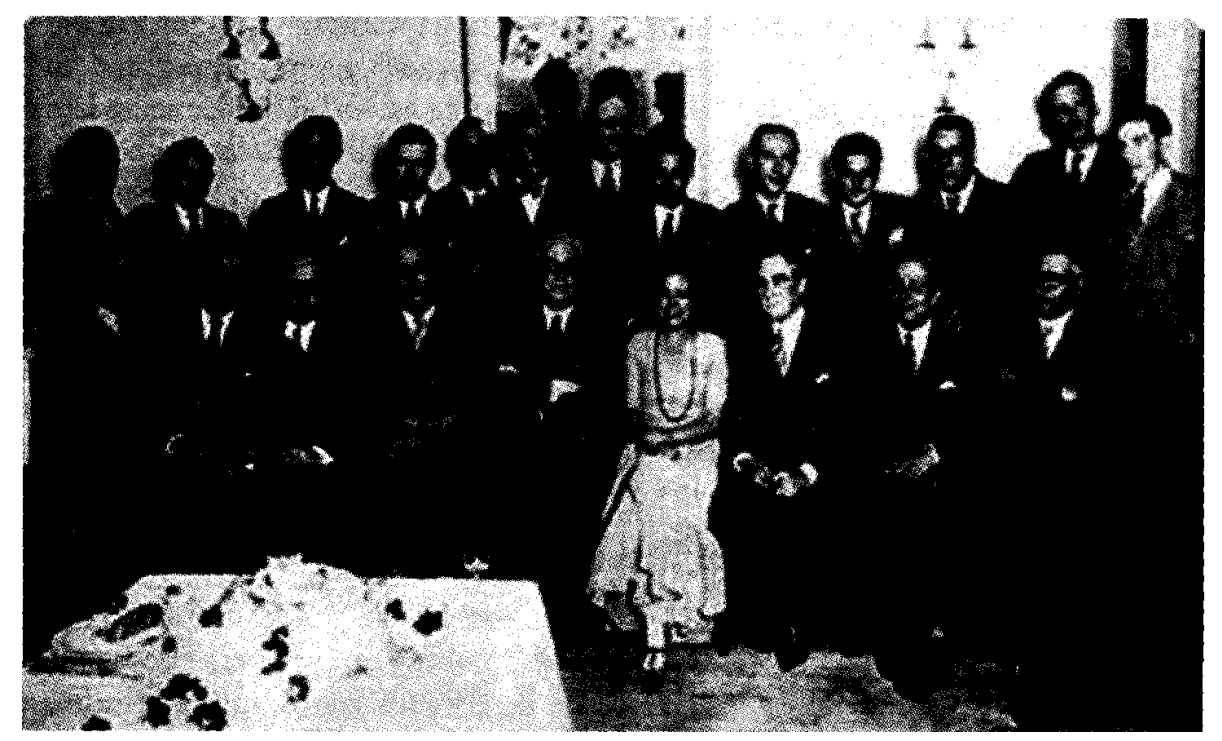

Comida a Enrique Diez-Canedo (2 de septiembre de 1932). De pie (de izquierda a derecha): Florisel, Xavier Villaurrutia, Francisco Monterde, José Gorostiza, Carlos Pellicer, Manuel Toussaint, Artemio del Valle-Arizpe, Xavier Icaza, Enrique González Rojo, Bernardo Ortíz de Montellano, GuillermoJiménez, Jorge Cuesta y Celestino Gorostiza. Sentados:Samuel Ramos, Roberto Montenegro, Julio Torri, Salvador Novo, Enrique Diez-Canedo, Palma Guillén, Gonzalo Zaldumbide, Enrique González Martínez y Mariano Azuela. 